\title{
Validity of a modified shuttle test in adult cystic fibrosis
}

\author{
Judy Bradley, Jennifer Howard, Eric Wallace, Stuart Elborn
}

\begin{abstract}
Background-The purpose of this study was to provide some evidence of the validity of a modified shuttle test (MST) by comparing performance on the MST with peak oxygen consumption (Vंo ${ }_{2}$ peak) measured during a treadmill test in a group of adult patients with cystic fibrosis. Method-Twenty patients with stable cystic fibrosis performed a ramped maximal treadmill test (STEEP protocol) and the MST using a randomised balanced design.

Results-The relationship between the distance achieved on the MST and $\dot{V}_{2}$ peak was strong $(r=0.95, p<0.01)$ with $90 \%$ of the variance in $\dot{\mathrm{Vo}}_{2}$ peak explained by the variance in MST distance. The relationship was represented by the regression equation (with $95 \%$ confidence intervals) $\dot{V}_{\mathrm{O}_{2} \text { peak }}=6.83(2.85$ to 10.80$)+$ $0.028(0.019$ to 0.024$) \times$ MST distance. Conclusion-This study provides evidence of the construct validity of the MST as an objective measure of exercise capacity in adults with cystic fibrosis.

(Thorax 1999;54:437-439)
\end{abstract}

Keywords: modified shuttle test; cystic fibrosis

Sport and Exercise

Sciences, University of Ulster at Jordanstown, Co. Antrim BT37 0QB,

UK

J Bradley

E Wallace

Adult Cystic Fibrosis Unit, Belfast City Hospital, Belfast, Co. Antrim BT9 $7 \mathrm{AB}$, UK

J Howard

S Elborn

Correspondence to: Dr S Elborn.

Received 21 April 1998 Returned to author 8 July 1998

Revised manuscript received

2 October 1998

Accepted for publication

1 December 1998

the reliability, validity, and sensitivity of many of these tests. ${ }^{12}$

The shuttle walking test is an incremental overcomes many of the problems associated with existing informal exercise tests. The original authors of the shuttle walking test have shown this test to be a reliable (after just one practice test), valid, and sensitive measure of exercise capacity in patients with chronic obstructive pulmonary disease..$^{3-5}$ We have carried out preliminary work with the shuttle walking test in adult patients with cystic fibrosis, and have shown that the walking speeds in the original test (up to a maximum of $2.37 \mathrm{~m} / \mathrm{s}$ ) do not elicit a maximal response in adult patients with cystic fibrosis and minimal disability as well as in patients with more severe disability. On the basis of these preliminary findings the original test was modified by the addition of three levels and, further, by permitting the patients to run. The additional stages to the original 12 stage test were: level 13, 5.63 mph, 15 shuttles; level $14,6.00 \mathrm{mph}, 16$ shuttles; and level 15, $6.38 \mathrm{mph}, 17$ shuttles. It was hypothesised that this modified shuttle test (MST) could be used to measure peak exercise capacity objectively in adult patients with cystic fibrosis. The aim of this study was therefore to compare patients' performance on the MST with peak oxygen consumption (V $\mathrm{O}_{2}$ peak) measured directly during a treadmill test.

\section{Methods}

Twenty patients (14 men) of mean (SD) age 25 (7) years, weight 58 (8) $\mathrm{kg}$, height 1.68 (0.08) metres volunteered for the study. All patients had been familiarised with the MST and the treadmill test prior to entry into the study. Patients undertook the treadmill test on one visit to the hospital and the MST on a separate visit. The order of the tests was randomised in a counterbalanced design. The mean (SD) duration between visits was 7 (4) days. The tests were performed at approximately the same time each day. Baseline spirometric measurements (Vitalograph Alpha), resting oxygen saturations and resting heart rate (Ohmeda $\mathrm{SaO}_{2}$ monitor with ear probe), and rating of perceived breathlessness (Borg scale $^{6}$ ) were recorded before the exercise test on each study day. The study was approved by the hospital ethical committee and informed consent was obtained from all patients. externally paced informal exercise test which
TREADMILL TEST

The treadmill test was a symptom limited maximal exercise test performed according to 
the standardised treadmill exponential exercise protocol (STEEP). ${ }^{7}$ During the treadmill test measures of $\dot{\mathrm{V}}_{2}(\mathrm{ml} / \mathrm{min}), \dot{\mathrm{V}}_{2}(\mathrm{ml} / \mathrm{min})$, and minute ventilation (VE, $1 / \mathrm{min}$ ) were recorded at $15 \mathrm{~s}$ intervals (PK Morgan). The equation forced expiratory volume in one second $\left(\mathrm{FEV}_{1}\right)$ $\times 35$ was used to predict maximum voluntary ventilation (MVV). ${ }^{8}$ The heart rate was measured at one minute intervals using a 12 lead electrocardiogram (Model Marguette Case 15) and $\mathrm{SaO}_{2}$ was continuously monitored using an Ohmeda $\mathrm{SaO}_{2}$ monitor. At the end of the test the peak heart rate, $\mathrm{SaO}_{2}$, and peak rate of perceived breathlessness were recorded. Reasons for stopping or failing to maintain the correct pace were also recorded.

\section{SHUTTLE TEST}

Using the 15 level MST, patients were required to walk/run at increasing speeds back and forth on a 10 metre course. ${ }^{3}$ They were accompanied by an operator during the first minute of the test to help them pace themselves with the audiosignal. At the end of each level the patients were also told to go a little faster and were reminded that they were permitted to run at any time during the test. Patients continued with the test until they were unable to do so or failed to maintain the set pace. ${ }^{3}$ Heart rate was measured at $15 \mathrm{~s}$ intervals using a short range telemetry device (Polar Sports Tester) and $\mathrm{SaO}_{2}$ was continuously monitored using an Ohmeda $\mathrm{SaO}_{2}$ monitor. At the end of the test the peak heart rate, $\mathrm{SaO}_{2}$, and peak rating of perceived breathlessness were recorded. Reasons for stopping or failing to maintain the correct pace were also recorded.

\section{Results}

Lung function $\left(\mathrm{FEV}_{1}\right)$ ranged from $17 \%$ to $96 \%$ predicted normal, indicating that the patients exhibited a wide variety of disease impairment. Table 1 shows that there were no significant differences between study days in baseline test parameters $\left(\mathrm{FEV}_{1}\right.$, resting heart rate, resting rating of perceived breathlessness, resting $\mathrm{SaO}_{2}$ ). Furthermore, there were no significant differences between tests in comparable physiological responses to exercise.

Table 1 Mean (SD) baseline characteristics and physiological responses to exercise testing of patients

\begin{tabular}{|c|c|c|c|}
\hline Parameter & Shuttle test & Treadmill test & $p$ value \\
\hline \multicolumn{4}{|l|}{ Baseline characteristics } \\
\hline Age (years) & $25(7)$ & - & - \\
\hline Weight $(\mathrm{kg})$ & $58(8)$ & - & - \\
\hline Height $(\mathrm{m})$ & $1.67(0.008)$ & - & - \\
\hline $\mathrm{FEV}_{1}(\%$ pred $)$ & $49(23)$ & $48(25)$ & 0.31 \\
\hline $\mathrm{SaO}_{2}$ & $94(3)$ & $94(3)$ & 0.39 \\
\hline Resting heart rate (beats/min) & $95(12)$ & $97(17)$ & 0.56 \\
\hline Resting heart rate (\% pred max) & $49(7)$ & $50(8)$ & 0.46 \\
\hline Resting rating perceived breathlessness & $0(1)$ & $0(1)$ & 0.89 \\
\hline \multicolumn{4}{|l|}{ Physiological responses } \\
\hline V $\mathrm{O}_{2}$ peak $(\mathrm{ml} / \mathrm{kg} / \mathrm{min})$ & $32.85(10.36)$ & - & - \\
\hline$\dot{\mathrm{V}} \mathrm{O}_{2}$ peak (\% pred) & $73.45(26.27)$ & - & - \\
\hline VEmax $(1 / \min )$ & $57.76(20.01)$ & - & - \\
\hline VE $(\%$ pred $)$ & $101(40)$ & - & - \\
\hline MST distance (m) & - & 929 (335) & - \\
\hline Max heart rate (beats/min) & $171(23)$ & $169(24)$ & 0.90 \\
\hline Max heart rate (\% pred) & $87(10)$ & $86(11)$ & 0.95 \\
\hline Peak rate perceived breathlessness & $6(1)$ & $6(1)$ & 0.90 \\
\hline End $\mathrm{SaO}_{2}$ & $89(7)$ & $88(7)$ & 0.10 \\
\hline
\end{tabular}

$\mathrm{FEV}_{1}=$ forced expiratory volume in one second; $\mathrm{SaO}_{2}=$ oxygen saturation; $\dot{\mathrm{V}}_{2}$ peak = peak oxygen consumption; $\mathrm{VE}=$ minute ventilation; $\mathrm{MST}=$ modified shuttle test.

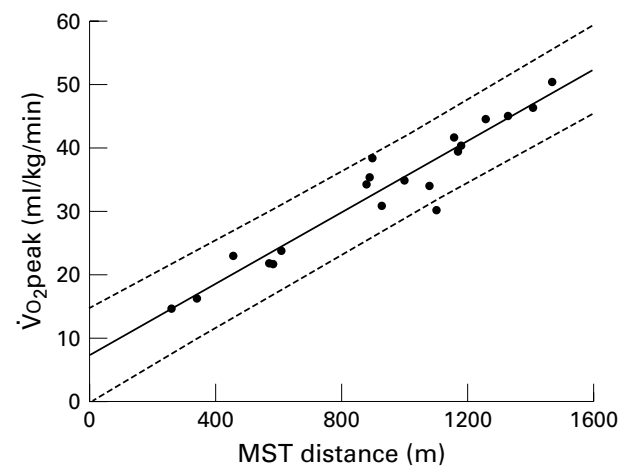

Figure 1 Regression line (with 95\% confidence intervals) for the relationship between performance on the modified shuttle test (MST) and peak oxygen consumption ( $V_{O_{2}}$ peak) measured during treadmill testing.

A significant and moderately strong relationship was found between the distance achieved on the MST and lung function (MST vs $\mathrm{FEV}_{1} \%$ predicted: $\left.r=0.70, \mathrm{p}=0.001\right)$ and between $\dot{\mathrm{V}}_{2}$ peak and lung function $\left(\dot{\mathrm{V}}_{2}\right.$ peak vs $\mathrm{FEV}_{1} \%$ predicted: $\left.r=0.78, \mathrm{p}<0.001\right)$. The relationship between the distance achieved on the MST and directly measured $\dot{\mathrm{V}}_{2}$ peak was strong $(r=0.95, \mathrm{p}<0.00)$ with $90 \%$ of the variance in $\dot{\mathrm{V}}_{2}$ peak explained by the variance in the MST distance. Using methods adopted from the authors of the original test, ${ }^{4}$ regression analysis was used to further describe the nature of the relationship between $\dot{\mathrm{V}}_{2}$ peak and MST performance. The relationship was represented by the regression equation and $95 \%$ confidence intervals:

$\dot{\mathrm{V}}_{\mathrm{O}_{2}}$ peak $=6.83(2.85$ to 10.80$)+0.028$ $(0.019$ to 0.024$) \times$ MST distance (fig 1$)$.

\section{Discussion}

The purpose of this study was to determine the validity of the MST as a measure of exercise capacity in adults with cystic fibrosis. The results show that there was a strong relationship between $\dot{\mathrm{V}}_{2}$ peak and MST performance in patients with cystic fibrosis and varying degrees of lung function impairment. Ninety percent of the variation of directly measured $\dot{\mathrm{V}}_{2}$ peak is explained by the variation in MST performance. This compares very favourably with the original test in which the shuttle walking test performance explained $77.4 \%$ of the variance in directly measured $\dot{\mathrm{V}}_{2}$. Many cystic fibrosis clinicians have no access to formal exercise testing equipment and the regression analysis used in this study provides additional information to such individuals on the nature of the relationship between $\dot{\mathrm{V}}_{2}$ peak and MST performance. There was no significant difference between peak heart rate and peak rating of perceived breathlessness recorded during both exercise tests, which indicates the effectiveness of the MST to evoke a symptom limited exercise response in both mildly and more severely compromised adults with cystic fibrosis.

Most of the patients in the present study encroached on their pulmonary reserve during exercise testing (mean peak VE $>70 \%$ MVV). None of the patients reached their maximum predicted heart rate, as determined by the age related equation (220-age), and "shortness of 
breath" and "fatigue" were the most common reasons reported for stopping the exercise test. These findings support the assertion that ventilatory factors rather than cardiovascular factors limit exercise tolerance in cystic fibrosis. ${ }^{9}$

The relationship between lung function and $\dot{V}_{2}$ peak was moderate. This finding supports previous work which indicated that impaired pulmonary function limits exercise capacity. ${ }^{10}$ Lung function is not a good predictor of exercise capacity because of wide intersubject variability of exercise capacity in patients with comparable lung function. In the present study oxygen desaturation (more than $5 \%$ fall in $\left.\mathrm{SaO}_{2}\right)^{11}$ occurred in all patients with $\mathrm{FEV}_{1}$ less than $35 \%$ predicted, and in two of the patients with $\mathrm{FEV}_{1}$ of $43 \%$ and $50 \%$. Exercises tests to establish if exercise induced desaturation occurs are therefore a necessary prerequisite to exercise prescription in cystic fibrosis. Oxygen saturation should also be intermittently monitored during exercise programmes and, if necessary, supplemental oxygen should be used to avoid oxygen desaturation.

This study has shown that there is a strong relationship between MST performance and $\dot{\mathrm{V}}_{2}$ peak in adults with cystic fibrosis and thus provides evidence of the validity of this test as a measure of peak exercise capacity in adult cystic fibrosis. Further work is required to establish the intertest reliability, test-retest reliability, and the sensitivity to change of the MST in adult patients with cystic fibrosis.

The authors would like to thank Mrs Jackie Megarry for her technical assistance with this research study.

1 Shephard RJ. Tests of maximum oxygen intake. A critical review. Sports Med 1984:1:99-124.

2 Swinburn CR, Wakefield JM, Jones PW. Performance, ventilation and oxygen consumption in three different types of exercise test in patients with chronic obstructive lung exercise test in patients with

3 Singh SJ, Morgan MDL, Scott S, et al. Development of a shuttle walking test of disability in patients with chronic shuttle walking test of disability in patients

4 Singh SJ, Morgan MDL, Hardman AE, et al. Comparison of oxygen uptake during a conventional treadmill test and the shuttle walk test in chronic airflow limitation. Eur Respir $\mathcal{F}$ 1994;7:2016-20.

5 Singh SJ, Morgan MDL. The use of the shuttle walking test to assess disability before and after rehabilitation in chronic respiratory disease. Pediatr Pulmonology 1996;340:303.

6 Borg GAV. Psychophysical basis of perceived exertion. Med Sci Sports Exerc 1982;14:377-81.

7 Riley M, Northridge DB, Henderson E, et al. The use of the exponential protocol for bicycle and treadmill testing in patients with chronic heart failure. Eur Heart $\mathcal{F}$ 1992;13: patients

8 Gabdevia B, Hugh-Jones P. Terminology for measurements of ventilatory capacity. Thorax 1957;1:290-3.

9 Cerny FJ, Pullano TP, Cropp GJA. Cardiorespiratory adapCerny FJ, Pullano TP, Cropp GJA. Cardiorespiratory adap-
tations to exercise in cystic fibrosis. Am Rev Respir Dis

10 Webb AK, Dodd ME. Exercise and cystic fibrosis. $f R$ Soc Med 1995;88(Suppl 25):30-6.

11 Marcotte JE, Grisdale R, Levison H, et al. Multiple factors limit exercise tolerance in cystic fibrosis. Pediatr Pulmonol 1986;2:274-81.

\section{Collagen degrading activity associated with Mycobacterium species}

Departamento de Biología Celular,

Instituto Nacional de

Cardiología "Ignacio

Chávez", Juan

Badiano 1, Tlalpan

14080, Mexico

F Massó

A Paéz

E Varela

L F Montaño

Departamento de

Biología Desarrollo,

Instituto de

Investigaciones

Biomédicas, UNAM,

Mexico

L Díaz de León

Departamento de

Bioquímica, Instituto

Nacional

Enfermedades

Respiratorias, Tlalpan,

México

E Zenteno

Correspondence to: Dr L F Montaño.

Received 13 August 1998 Returned to author 28 September 1998 Revised manuscript received 20 November 1998 Accepted for publication 5 January 1999

F Massó, A Paéz, E Varela, L Díaz de León, E Zenteno, L F Montaño

\begin{abstract}
Background-The mechanism of Mycobacterium tuberculosis penetration into tissues is poorly understood but it is reasonable to assume that there is a contribution from proteases capable of disrupting the extracellular matrix of the pulmonary epithelium and the blood vessels. A study was undertaken to identify and characterise collagen degrading activity of $M$ tuberculosis.

Methods-Culture filtrate protein extract (CFPE) was obtained from reference mycobacterial strains and mycobacteria isolated from patients with tuberculosis. The collagen degrading activity of CFPE was determined according to the method of Johnson-Wint using ${ }^{3} \mathrm{H}$-type I collagen. The enzyme was identified by the Birkedal-Hansen and Taylor method and its molecular mass determined by SDSPAGE and Sephacryl S-300 gel filtration chromatography using an electroelution purified enzyme.
\end{abstract}

Results-CFPE from Mycobacterium tuberculosis strain H37Rv showed collagenolytic activity that was four times higher than that of the avirulent strain H37Ra. The $75 \mathrm{kDa}$ enzyme responsible was divalent cation dependent. Other mycobacterial species and those isolated from patients with tuberculosis also had collagen degrading activity.

Conclusions-Mycobacterium species possess a metalloprotease with collagen degrading activity. The highest enzymatic activity was found in the virulent reference strain H37Rv.

(Thorax 1999;54:439-441)

Keywords: Mycobacterium tuberculosis; collagenase; metalloprotease

An increasing number of microorganisms, many of which are putative human pathogens, produce enzymes which degrade collagen. ${ }^{1}$ The mechanism of penetration of Mycobacterium tuberculosis into the tissues and bloodstream is poorly understood but, as with other lung diseases, ${ }^{23}$ gastrointestinal infections, ${ }^{4}$ and necrotic conditions, ${ }^{5}$ it is reasonable to assume that there is a contribution from proteases capable of disrupting the 


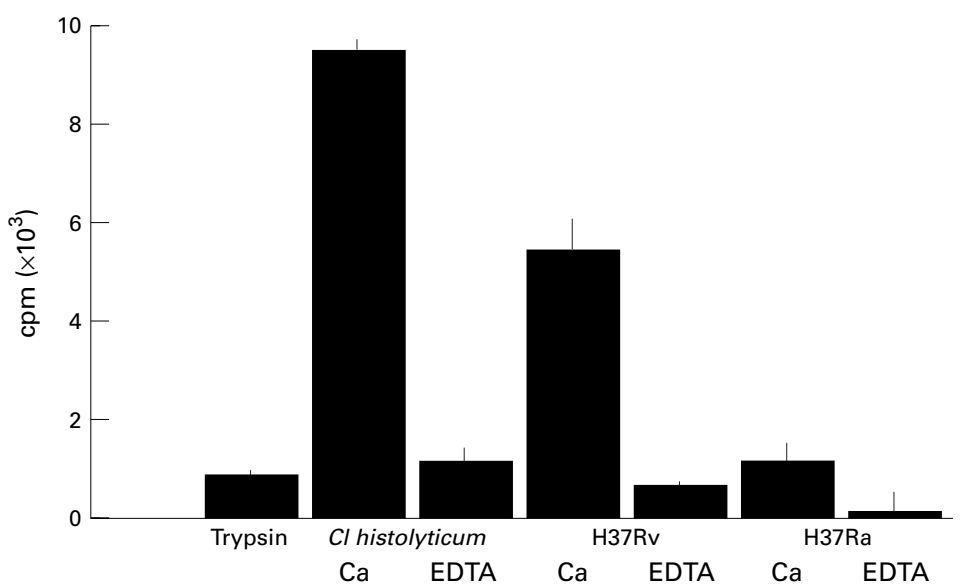

Figure 1 Collagenolytic activity of $M$ tuberculosis $H 37 R v$ and H37Ra culture filtrate protein extract in the presence of calcium or EDTA as calcium chelant. Results are expressed as mean (SE). Background counts per minute (cpm) have already been subtracted. Maximum activity, calculated assuming that all the radioactivity (12 $500 \mathrm{cpm} /$ well) was liberated, corresponded to Cl histolyticum (75.5).

extracellular matrix of the pulmonary epithelium and the blood vessels. The aim of this study was to identify and characterise collagenolytic activity in Mycobacterium reference strains and in those isolated from patients with tuberculosis.

\section{Methods}

MYCOBACTERIAL CULTURES

First early morning expectoration samples from two patients with pulmonary tuberculosis and two with miliary tuberculosis, pleural fluid from two patients with pulmonary tuberculosis and one with miliary tuberculosis, and the first early morning urine sample from one patient with renal tuberculosis were collected, seeded, grown, and identified as $M$ tuberculosis by the National Tuberculosis Reference Laboratory. The following ATCC reference strains were donated by the referred laboratory and CENID Microbiología, México: $M$ tuberculosis H37Rv and H37Ra (virulent and attenuated mycobacteria isolated from a human lung, used for susceptibility testing ${ }^{6}$ ),$M$ kansasii, $M$ fortuitum, $M$ microti, $M$ terrae, $M$ avium, and $M$ gordonae. These strains were seeded in protein-free Proskauer-Beck-Youmans (PBY) medium and maintained at $37^{\circ} \mathrm{C}$ for $7-9$ weeks before bacteria were harvested. ${ }^{8}$ Some cultures were maintained for as long as 12 weeks before harvesting.

CULTURE FILTRATE PROTEIN EXTRACT (CFPE)

The culture medium was separated from the bacterial mass by filtration through $0.45 \mu \mathrm{m}$ and $0.22 \mu \mathrm{m}$ membrane filters (Millipore Corp). Proteins were precipitated with solid ammonium sulphate crystals ( $80 \%$ final saturation) and centrifuged for 30 minutes at $16000 \mathrm{~g}$. The precipitate, suspended in $5 \mathrm{ml}$ phosphate buffered saline (PBS) containing $0.2 \mathrm{mg} / \mathrm{ml}$ phenylmethylsulphonyl fluoride (Sigma Chemicals), was dialysed extensively against PBS and $0.5 \mathrm{ml}$ aliquots $(6 \mathrm{mg} / \mathrm{ml}$ ) were stored in liquid nitrogen until used. Some filtrates were precipitated at $40 \%$ and $60 \%$ $\left(\mathrm{NH}_{4}\right)_{2} \mathrm{SO}_{4}$ final saturation.
COLLAGEN

Collagen was obtained from the skin of two month old female Wistar rats according to the method described by Epstein. ${ }^{9}$ The specific activity of radiolabelled collagen was $1 \times$ $10^{6} \mathrm{cpm} / \mathrm{mg}$ of protein.

COLLAGENOLYTIC ASSAY

The enzymatic activity was determined according to the method of Johnson-Wint ${ }^{10}$ using $120 \mu \mathrm{g}$ CFPE and $12500 \mathrm{cpm}$ radioactive collagen/well. Some experiments were performed with $20 \mathrm{mM}$ /well EDTA tetrasodium salt (Sigma Chemicals). Controls included buffer, $0.001 \%$ trypsin (type IX from porcine pancreas), and Clostridium histolyticum collagenase (high purity, type III fraction A).

\section{COLLAGENASE IDENTIFICATION}

The enzyme was identified using a modification of the method described by Taylor and Birkedal-Hansen ${ }^{11}$ that included elimination of SDS from the gel with 3\% Triton X-100 and overnight incubation at $37^{\circ} \mathrm{C}$. The region with collagenolytic activity in the CFPE containing gel ( $\beta$-mercaptoethanol reduced and boiled sample/lane in $10 \%$ slab gels ${ }^{12}$ ) was located, purified by electroelution, dialysed, lyophilised, and kept at $-20^{\circ} \mathrm{C}$ until used. The nondenatured state of the substrate was corroborated by the inclusion of trypsin, an enzyme incapable of breaking down collagen but highly active upon gelatin.

MOLECULAR MASS DETERMINATION

The molecular mass of the enzyme (75 000 by SDS-PAGE) was determined by Sephacryl S-300 gel filtration chromatography. $500 \mu \mathrm{g}$ of enzyme partially purified by electroelution were suspended in $0.05 \mathrm{M}$ Tris $\mathrm{HCl}$ buffer $(\mathrm{pH}$ 7.5) containing $4 \mathrm{mM} \mathrm{CaCl}$, poured onto a $1.2 \times 100 \mathrm{~cm}$ glass column previously equilibrated with the same buffer, and eluted with the Tris $\mathrm{HCl}$ buffer at a flow rate of $12 \mathrm{ml} /$ hour. Standards included horse heart myoglobin $(17 \mathrm{kDa})$, bovine serum albumin (66 kDa), purified human IgG $(150 \mathrm{kDa})$, and bovine liver catalase $(240 \mathrm{kDa})$. The activity of each fraction was tested as described above.

\section{Results}

The collagenolytic activity of CFPE from $\mathrm{H} 37 \mathrm{Rv}$ was four times higher than that from $\mathrm{H} 37 \mathrm{Ra}$ (43.4\% and 9.1\%, respectively). Addition of EDTA to the H37Rv CFPE blocked the enzymatic activity by $88 \%$, thus establishing that the enzyme in the virulent strain was dependent on divalent cations (fig 1). Similar results were obtained with replicate cultures. The enzymatic activity was secondary to a $75 \mathrm{kDa}$ protein which was clearly established by the degradation of collagen containing gels and molecular mass determination by Sephacryl S-300 gel filtration chromatography.

The collagenolytic activity was not changed by the use of ammonium sulphate saturation to precipitate the CFPE, the amount of H37Rv CFPE precipitated with a final ammonium sulphate saturation of $40 \%, 60 \%$ and $80 \%$ being 
Table 1 Mean (SE) collagenolytic activity of culture filtrates obtained from various mycobacterial species

\begin{tabular}{|c|c|c|c|c|}
\hline & \multicolumn{2}{|l|}{ With Ca } & \multicolumn{2}{|l|}{ With EDTA } \\
\hline & $\begin{array}{l}\text { Counts per minute } \\
(c p m)\end{array}$ & $\begin{array}{l}\text { Enzyme } \\
\text { activity }\end{array}$ & $\begin{array}{l}\text { Counts per minute } \\
(c p m)\end{array}$ & $\begin{array}{l}\text { Enzyme } \\
\text { activity }\end{array}$ \\
\hline Trypsin & $1088(203)$ & 8.7 & $528(18)$ & 4.2 \\
\hline Cl histolyticum & $10982(904)$ & 87.8 & $2888(878)$ & 23.1 \\
\hline$M$ microti & $3234(113)$ & 25.8 & $1094(140)$ & 8.7 \\
\hline$M$ kansasii & 1038 (348) & 8.3 & $888(282)$ & 7.1 \\
\hline$M$ avium & $2621(229)$ & 20.9 & $1277(305)$ & 10.2 \\
\hline$M$ terrae & $768(63)$ & 6.1 & $433(69)$ & 3.4 \\
\hline$M$ gordonae & $542(74)$ & 4.3 & $485(45)$ & 3.8 \\
\hline$M$ fortuitum & $272(33)$ & 2.1 & $174(46)$ & 1.3 \\
\hline
\end{tabular}

Background cpm have already been subtracted. The percentage of activity was calculated assuming that all the radioactivity $(12500 \mathrm{cpm} / \mathrm{well})$ was liberated by the enzyme.

Table 2 Mean (SE) collagenolytic activity of culture filtrates obtained from mycobacteria isolated from patients with tuberculosis

\begin{tabular}{llllllr}
\hline & \multicolumn{3}{l}{ With Ca } & & & With EDTA \\
\cline { 3 - 4 } \cline { 6 - 7 } Diagnosis * & Sourcet & $\begin{array}{l}\text { Counts per } \\
\text { minute (cpm) }\end{array}$ & $\begin{array}{l}\text { Enzyme } \\
\text { activity }\end{array}$ & & $\begin{array}{l}\text { Counts per } \\
\text { minute (cpm) }\end{array}$ & $\begin{array}{l}\text { Enzyme } \\
\text { activity }\end{array}$ \\
\hline Trypsin & & $792(130)$ & 6.3 & & $404(103)$ & 3.2 \\
Cl histolyticum & & $9763(559)$ & 78.1 & & $2367(362)$ & 18.9 \\
Pulmonary TB & Sputum & $1160(284)$ & 9.2 & & $510(462)$ & 4.0 \\
Pulmonary TB & Sputum & $4198(204)$ & 33.5 & & $684(642)$ & 5.4 \\
Pulmonary TB & Pleural fluid & $1783(462)$ & 14.2 & & $348(90)$ & 2.7 \\
Pulmonary TB & Pleural fluid & $1376(248)$ & 11.0 & & $1142(108)$ & 9.1 \\
Miliary TB & Sputum & $2276(98)$ & 18.2 & & $874(138)$ & 6.9 \\
Miliary TB & Sputum & $4986(230)$ & 39.8 & & $566(32)$ & 4.5 \\
Miliary TB & Pleural fluid & $2864(127)$ & 22.9 & & $814(175)$ & 6.5 \\
Renal TB & Urine & $2316(224)$ & 18.5 & & $1238(148)$ & 9.9 \\
\hline
\end{tabular}

*All patients were PPD positive.

tSource refers to the secretion from which the mycobacteria were isolated.

Background cpm have already been subtracted. The percentage of activity was calculated assuming that all the radioactivity $(12500 \mathrm{cpm} /$ well) was liberated by the enzyme.

4380 (304) cpm, 4224 (215) cpm, and 4146 (182) $\mathrm{cpm}$, respectively. To determine the influence of culture time on enzymatic activity, five $\mathrm{H} 37 \mathrm{Rv}$ cultures were seeded and harvested after $32,38,46,70$, and 103 days of culture and had CFPE activity of $20 \%, 29 \%, 34 \%, 33 \%$, and $15 \%$, respectively, indicating that the collagenolytic activity decays with time.

The collagenolytic activity of CFPE obtained from mycobacteria other than $M$ tuberculosis was also tested. $M$ microti showed the highest level of activity followed by $M$ avium, $M$ kansasii, $M$ terrae, $M$ gordonae, and $M$ fortuitum which had the least activity (table 1). Enzymatic variability was also observed in culture filtrates obtained from mycobacteria isolated from patients with tuberculosis (table 2).

\section{Discussion}

The presence of collagenolytic activity in the CFPE of $M$ tuberculosis $\mathrm{H} 37 \mathrm{Rv}$ strain was secondary to a $75 \mathrm{kDa}$ enzyme whose activity was dependent on divalent cations and was blocked by EDTA, suggesting a mechanism of noncompetitive inhibition. These characteristics are similar to those reported for Clostridium histolyticum collagenase ${ }^{13}$ and the majority of collagenases. ${ }^{14}$ Even though we recognise the possible influence of collagenase degradation before harvesting, the differences between the CFPE samples of $\mathrm{H} 37 \mathrm{Rv}$ virulent and H37Ra avirulent mycobacterial strains were striking and were independent of batch to batch variations, source of seed, and time of culture.

None of the mycobacteria we tested had activity greater than $M$ tuberculosis $\mathrm{H} 37 \mathrm{Rv}$. As in the case of catalase activity, once considered a virulence factor, ${ }^{15}$ collagen degrading activity is important but not vital in the pathogenesis of the disease since there was no uniform activity in $M$ avium and $M$ kansasii, both of which induce tuberculosis. $M$ fortuitum and the non-disease inducers $M$ terrae and $M$ gordonae had very poor enzyme activity. Although tissue destruction is secondary to an enhanced cellular immune response, mycobacterial metalloproteinases might be important for bacterial penetration $^{116}$ as has been shown with other infectious agents. ${ }^{417}$ Despite the above considerations, it was interesting to observe that $M$ tuberculosis isolated from tuberculosis patients with different clinical syndromes (renal, miliary, pulmonary) had greater activity than the avirulent reference strain H37Ra.

Our results confirm the presence of collagen degrading enzymatic activity in the culture filtrate protein extract of all the mycobacteria tested. Extracellular proteases may also play a role in the pathogenesis of mycobacterial infection. However, the recent resolution of the genome for $M$ tuberculosis H37Rv (website: www.sanger.ac.uk) predicts at least 38 genes coding for proteins of virulence and more than 250 macromolecular and/or micromolecular degrading proteins. One of these, the product of gene Rv0198c, a zinc metalloprotease with a molecular weight of $73.8 \mathrm{kDa}$, is similar to the enzyme we describe in this work.

1 Harrington DJ. Bacterial collagenases and collagendegrading enzymes and their potential role in human disease. Infect Immun 1996;64:1885-91.

2 Bruce MC, Poncz I, Klinger JD, et al. Biochemical and pathologic evidence for proteolytic destruction of lung connective tissue in cystic fibrosis. Am Rev Respir Dis 1985; 132:529-35.

3 Liener IE, Twumasi DY. Proteases from purulent sputum. Purification and properties of the elastase and chemotrypsinlike enzymes. F Biol Chem 1977;252:1917-26.

4 Serrano JJ, De la Garza M, Moreno MA, et al. Entamoeba histolytica: electrodense granule secretion, collagenase activity and virulence are altered in the cytoskeleton mutant BG-3. Mol Microbiol 1994;11:787-92.

5 Wright LG, Atkinson RK. The involvement of collagenase in the necrosis induced by the bites of some spiders. Comp Biochem Physiol 1992;102:125-8.

6 Van Soolingen D, Hoogenboezem T, de Haas PE, et al. A novel pathogenic taxon of the Mycobacterium tuberculosis complex, Canetti: characterization of an exceptional isolate from Africa. Int $\mathcal{7}$ Syst Bacteriol 1997;47:1236-45.

7 McMurray DN, Carlomagno MA, Cumberland PA. Respiratory infection with attenuated Mycobacterium tuberculosis H37Ra in malnourished guinea pigs. Infect Immun 1983;39: 793-9.

8 Parra C, Montaño LF, Huesca M, et al. Inhibition of mitogenesis induced by phytohemagglutinin and Lens culinaris lectin in adherent-cell supernatants treated with pronaris lectin in adherent-cell supernatants treated with pro-
tein extract of Mycobacterium tuberculosis. Infect Immun tein extract of $M$

9 Epstein EH. [ $\left.\alpha_{1}(\mathrm{III})\right]_{3}$ human skin collagen. f Biol Chem 1974;249:3225-31.

10 Johnson-Wint B. A quantitative collagen film collagenase assay for large number of samples. Anal Biochem 1980;104: 175-81.

11 Taylor RE, Birkedal-Hansen H. Detergent activation of latent collagenase and resolution of its component molecules. Biochem Biophys Res Commun 1982;107:1173-8.

12 Laemmli UK. Cleavage of structural proteins during the assembly of the head of bacteriophage T4. Nature 1970;227:680-5.

13 Van Wart HE, De Bond M. Characterization of the individual collagenases from Clostridium histolyticum. Biochemistry 1984;23:3085-91.

14 Harper E. Collagenases. Ann Rev Biochem 1980;49:106378.

15 Youmans GP. Virulence of mycobacteria. In: Youmans GP, ed. Tuberculosis. Philadelphia: WB Saunders, 1979: 194201.

16 Chang JC, Wysocki A, Tchou Wong KM, et al. Effect of Mycobacterium tuberculosis and its components on macrophages and the release of matrix metalloproteinases. Thorax 1996;51:306-11.

17 Merkel JR, Smith GC. Collagenolytic activity of Vibrio vulniticus: potential contribution on its invasiveness. Infect Immun 1982;35:1155-6. 